\title{
Grounded theory and leadership research: A critical realist perspective
}

\author{
Stephen Kempster ${ }^{\mathrm{a}}$, Ken W. Parry ${ }^{\mathrm{b}, *}$ \\ a Birmingham Business School, University of Birmingham, UK \\ b Faculty of Business, Bond University, Gold Coast, Queensland 4229, Australia
}

\section{A R T I C L E I N F O}

Available online 2 February 2011

\section{Keywords:}

Leadership

Grounded theory

Critical realism

\begin{abstract}
A B S T R A C T
The methodology of grounded theory has great potential to contribute to our understanding of leadership within particular substantive contexts. However, our notions of good science might constrain these contributions. We argue that for grounded theorists a tension might exist between a desire to create a contextualised theory of leadership and a desire for scientifically justified issues of validity and generalizable theory. We also explore how the outcome of grounded theory research can create a dissonance between theories that resonate with the reality they are designed to explore, and the theories that resonate with a particular yet dominant 'scientific' approach in the field of leadership studies - the philosophy of science commonly known as positivism. We examine the opportunities provided by an alternative philosophy of science, that of critical realism. We explore how conducting grounded theory research informed by critical realism might strengthen researchers' confidence to place emphasis on an understanding and explanation of contextualised leadership as a scientific goal, rather than the scientific goal of generalization through empirical replication. Two published accounts of grounded theory are critiqued candidly to help emphasise our arguments. We conclude by suggesting how critical realism can help shape and enhance grounded theory research into the phenomenon of leadership.
\end{abstract}

Crown Copyright @ 2010 Published by Elsevier Inc. All rights reserved.

\section{Introduction-new opportunities for leadership research}

Leadership research has begun to embrace the necessity of incorporating context and process into an understanding of the manifestation of the leadership phenomenon. The emphasis on the context and process of leadership is reflected most strongly in the methodology of grounded theory. As Parry (1998) claimed, this methodology is a fruitful direction for researchers of leadership to take. Until recently, the dominant methodologies shaping the field of leadership research have largely been positivist approaches in the form of hypothesis testing, quantitative data and quantitative analysis. However, such tenets of 'good' research might not be suitable for addressing leadership from a processual and context-based perspective and may similarly be inappropriate for the development of grounded theory. In so doing, they might stifle grounded theory's potential for significant contributions to the field of leadership.

Grounded theory is in a relative infancy as a research instrument as far as leadership research is concerned. The purpose of grounded theory is to generate credible descriptions and sense-making of peoples' actions and words that can be seen as applicable. 'A theory should fit the area from where it has been derived and in which it will be used', said Corbin and Strauss (2008: 300). However an important question that arises is whether the substantive claims of the grounded theory are justifiable to the broader 'scientific' community. In order to meet a claim of 'good' scientific research, grounded theory might be tempted to move from the original purpose, which is to generate an internally valid theory that makes sense to, and informs respondents from, the substantive context from which it was drawn. With the notable exceptions of Corbin and Strauss (2008) and Charmaz (2006)

\footnotetext{
* Corresponding author.

E-mail addresses: s.kempster@bham.ac.uk (S. Kempster), kparry@bond.edu.au (K.W. Parry).
} 
overt approaches to grounded theory have not generally sought to address this epistemological issue explicitly. Some of those latter approaches are presented by Egri and Herman (2000); Fassinger (2005); Jones and Kriflik (2006); Roberts (2002); Sookal and Hanlon (2002), and Xiao, Seagull, Mackenzie, and Klein (2004). A further epistemological dilemma of grounded theory is associated with 'remaining within the data' in the development of theory (Glaser \& Strauss, 1967) and has consistently been an issue for grounded theorists ever since - dealing with issues of objectivity in tandem with allowing personal experience to make sense of the data. Processes of generating grounded theory move from the empirical data to codes and themes, and to a hierarchy of levels of abstraction. We believe that such abstraction necessitates interpretation 'beyond surface-level data'. This interpretation might utilise metaphors (Lewis, 1999), related concepts, and even unrelated theories to supplement data interpretation in order to assist with the emergence of an explanatory substantive theory. Many grounded theorists might quietly voice that this is implicit within their practice. This is the concept to which Glaser (1978) was referring with the notion of theoretical sensitivity. In support, Corbin and Strauss (2008: 12) wrote, 'the analytic process should be relaxed, flexible and driven by insight gained through interaction with data rather than being overly structured and based only on procedures'. We wonder how else we might make sense of empirical data if we 'bracket out' our worldliness and common sense interpretations.

The necessity of this movement from the data toward abstraction resonates with the philosophy of science known as Critical Realism. Simply put, critical realism assumes that phenomena exist independent of an individual. Leadership is for example a phenomenon that is socially real (Fleetwood, 2004) in the sense that if humans did not exist it would not exist. For critical realists phenomena exist at the level of events and experiences but also at a deeper level that may not be observable. For example, leadership cannot be seen. Only its effects are observed and perhaps felt. Traditionally, grounded theory has been a method for researching phenomena that are observable, as argued implicitly rather than explicitly by Glaser and Strauss (1967). However, a central component of Parry's (1998) promotion of grounded theory as a method for researching leadership is that grounded theory can also be used to research 'non-observable' phenomena like leadership.

Through our interactions humans sustain the effect of leadership. We interpret it and sustain or elaborate its manifestation even though we may not be aware that we do so. Our understanding of leadership is constructed (Dachler \& Hosking, 1995; Meindl, 1995). Processes of its construction reflect historic antecedents that may be drawn from global stories, and drawn from local relationships. For critical realists the scientific project is to understand and explain phenomena. Reality is seen as a result of causal powers. Some powers are transitive (for example language and ideas) and others intransitive (like gravity). Some powers can be observed to cause effect others are less obvious. Some come into play in all circumstances and generate effect, while others vary in effect dependent on contexts. The complexity of the manifestation of social phenomenon for critical realists is thus contingent upon contexts. A context can be local or international. The examination of causal powers and their effect depends on the level of analysis of the research project. For example, the Globe Study (House et al., 2004) illustrates commonality of characteristics of leadership. However, a deeper examination of the processes of leadership in a specific organizational context might demonstrate dissimilarity with the Globe Study. The levels of similarity will vary, and are dependent upon context. It is to deeper examination and contextual detail that grounded theory is best suited. Critical realist researchers Pawson and Tilley (1997: 58) captured the sense of association between context (C), causal mechanisms (M) and the resulting effect or outcome ( $O$ ), which they called a CMO configuration. Fleetwood (2004) goes further to encapsulate context as a causal configuration of many mechanisms. He argues that explanations require a detailed illumination of causal mechanisms that are specific to the situation and common to a variety of contexts. If explanations of one context inform explanations of other contexts then we may be beginning to reveal something of how a phenomenon occurs. However, critical realists would be very cautious. At a local level of analysis, it is highly doubtful that two contexts can be the same, only at best similar. Thus, the manifestation of leadership might share similarities between contexts but good critical realist-informed science would necessitate a deeper understanding and explanation of how they are similar. In terms of generalization it cautions inference from one context to the next. Rather, critical realism seeks generalization through theoretical comparison.

It is this emphasis toward local contextualised understanding and explanation that suits the method of Grounded Theory. We argue here that such a philosophy of science could provide a strong foundation for grounded theory and a clear justification of its claims for internal validity without compromising the rigour of the research that ensues. In terms of leadership studies, the use of critical realist-informed grounded theory could help develop our understanding of how context and process shape the manifestation of leadership.

To illustrate our argument we will revisit and analyze two pieces of published data that used the grounded theory method. Through such analysis we believe we provide a contribution to understanding grounded theory through an alternate lens. In essence, we look at grounded theory from a critical realist perspective. We explore the opportunities provided to leadership studies by such a perspective. Prior to understanding grounded theory and the epistemological issues of critical realism, the growth in both qualitative research and the use of grounded theory is explored within the context of leadership studies.

\section{Qualitative leadership research and grounded theory}

The phenomenon of leadership is argued to have global presence, but appears to have a variety of attributes and is elusive in definitional clarity (House et al., 2004). In this paper we argue that such variation is contextually derived. There is an emerging consensus that, at a very high level of abstraction, leadership is argued to be a 'social and relational influence process that occurs within a social system' (Parry, 1998:87; consolidating discussion from range of commentators, notably Hunt, 1991; Locke et al., 1991; Yukl, 1998. In addition, such a view has been more recently echoed by Osborne, Hunt, \& Jauch, 2002; Bess \& Goldman, 2001; 
Zaccaro, Rittman, \& Marks, 2001). Key aspects of significance are the emphasis on social, contextual, processual and relational aspects of leadership.

A qualitative approach was argued by Conger (1998) and repeated again with Toegel (2002) to be the technique of choice for leadership studies. It enables the emergence of nuanced and contextualised richness within organizational structures, relationships and practices. Conger and Toegel (2002: 175) argued that leadership studies reflect a 'story of missed opportunities' as a result of the dominance of quantitative techniques on the field of leadership. Conger explains further that quantitative techniques assume a perspective wherein leadership is capable of being measured as a phenomenon that is static, well delineated and with universal dimensions. Conger's (1998) criticisms of quantitative techniques are associated with imposed limitations upon the examination of leadership. One imposed limitation is variation in organizational level (Yukl, 1998). Another is its dynamic and changeable character (Nadler \& Tushman, 1990). A third is the affect of the symbolic nature of leadership's social construction (Barker, 2001; and Sandberg, 2001). In essence the complex nature of the phenomenon of leadership varies by context. Day (2000) asserts that there is a dearth of specific, contextually based research. Similarly, there has been a call for a grounded, qualitative approach into the relational (Parry, 1998) and processual (Bryman, 2004; Conger, 1998; Day 2000; and Lowe \& Gardner, 2000) issues of leadership within discrete contexts (Bryman, Bresnen, Beardworth, \& Keil, 1988; see also Bryman, Stephens, \& Campo, 1996).

The notion of grounded theory analysis draws upon these elements as it seeks to produce a social theory of a particular phenomenon drawn from the relational experiences of participants within a discrete context (Fassinger, 2005). Thus, we reinforce the arguments of many scholars that grounded theory is an ideal research technique for leadership research. The key tenets of the grounded theory technique were first outlined by Glaser and Strauss (1967). They have been elaborated by both Glaser (1992) and Strauss and Corbin (1998) taking the technique in differing directions, but essentially anchoring the grounded theory technique in the qualitative harbour. In the field of leadership studies, Kan and Parry (2004) and Rowland and Parry (2009) have applied and extended the approach, placing great importance for leadership theory on the contextualised and processual elements of leadership manifestation and re-affirming the close association between grounded theory and qualitative research.

\subsection{The nature of grounded theory}

Grounded theory analysis enables a contextually rich perspective to be captured of the processes shaping leadership (Bryman, 1996; Parry, 1998; Egri \& Herman, 2000). Importantly, grounded theory can address a major criticism of qualitative studies - that it is accused of being 'journalism or unscientific' and lacks the rigour of 'good' scientific research (Silverman, 2001: 26). In a review of qualitative research, Bryman (2004) argues that too few qualitative research studies outline the detail of the approach to data analysis beyond broad headings.

In general, grounded theorists seek to move in a systematic way from categorizing data related to a phenomenon toward linking those categories. From this process an integrative picture or story is developed. From such analysis an explanation of the context-based phenomenon will emerge (adapted from Glaser \& Strauss, 1967). In applying grounded theory to the study of leadership, Parry (1998) suggested the following steps: Focus on the relational and processual elements of leadership in a particular context; apply qualitative analysis to qualitative data using the grounded theory technique to ensure rigour and to consider all variables (or causal mechanisms); generate an integrative theory with a hierarchy of abstraction; compare the theory to the extant literature and repeat the research in new contexts with the aim of building a formal theory. More recently, Kan and Parry (2004) and Rowland and Parry (2009) have demonstrated the value and validity that comes from greater use of data triangulation.

The principles of data gathering and analysis that are axiomatic of the grounded theory method are now expected as de rigueur within grounded theory research into leadership phenomena. Open coding and axial coding (Strauss \& Corbin, 1998) help to identify the variables of importance. Theoretical coding (Glaser \& Strauss, 1967; Glaser, 1978) helps to elaborate the dimensions of the properties of those variables. The Six Cs of grounded theory analysis (Glaser, 1978; Kan \& Parry, 2004) help to identify the relationships between these variables, and to determine the model that reflects the emerging theoretical explanation of the phenomenon. Theoretical sampling (Glaser \& Strauss, 1967; Glaser, 1978) helps the researcher to engage in several iterations of data gathering and analysis such that the emerging explanation is as valid and reliable as possible. Silverman (2001) has noted that constant comparison of these iterations of data gathering contributes to the validity of this research. By following these components of the grounded theory method, Jones and Kriflik (2006); Kan and Parry (2004); Kempster (2006), Xiao et al. (2004) and others are at the forefront of the application of grounded theory to leadership research.

In the context of leadership studies, qualitative research in general - including grounded theory - has been described as a 'poor cousin' to quantitative techniques and 'research and practice have paid a significant price for this deference' (Conger \& Toegel, 2002: 194). Such deference may in part be analogous to a child developing its own identity and a sense of self. We argue here that grounded theory needs to 'find itself' through becoming aware of its broader epistemological foundations; it is intended that this debate on critical realism might help in this regard.

\section{Grounded theory and leadership: The need for an epistemological foundation}

The need to explain the underlying presuppositions of scientific research is often taken for granted. Critical realism, like positivism is a philosophy of science. Positivism is predominant in our 'doing' of science, but other approaches which are less 
prominent or popular may make us reflect upon what constitutes 'good science'. This reflection is partly what we are attempting to achieve with this article.

Grounded theory adopts a contextual examination of social processes in organizations and such a focus will be argued to be in close accord with the underlying philosophy of critical realism. Critical realism is sometimes referred to as post-positivism (Groff, 2004). We are not seeking to conflate grounded theory with critical realism. Indeed, one can be a critical realism theorist without being a grounded theory theorist, and thus far grounded theorists have generally not been critical realists. Rather our argument is toward seeing the opportunities for leadership studies that may be stimulated by viewing grounded theory through a critical realist frame, or lens. First we need to clarify notions of positivism and compare and contrast this with critical realism - there is considerable overlap but also some important distinctions. Good science commonly requires the satisfaction of three tests: validity, reliability and generalizability. For positivists and critical realists these three tests are equally applicable. However they differ in terms of definition.

\subsection{Good science and generalizability}

Positivism is associated with an independent external reality and properties of reality need to be measured through objective methods, rather than inferred through sensation, reflection or intuition (Easterby Smith, Thorpe, \& Lowe, 2002: 29). In essence, there is no knowledge unless it is based on observed facts. A number of principles are common to this scientific belief. The first is to be independent and value-free. The observer must be objective and use objective tests. The second principle is that causation is established through a process of identifying a hypothesis that is tested and either proved or falsified through statistical measurement. The third is that such measurement is to be drawn from samples of sufficient size that inferences can be drawn. These principles are followed in order to demonstrate law-like regularities that explain reality.

These epistemological criteria invariably are not examined or scrutinised. The common usage of positivism is arguably internalised as scientific truth wherein the underlying epistemological justification is unnecessary (Sookal \& Hanlon, 2002). Such taken for granted assumptions undoubtedly have influenced approaches to 'doing' grounded theory. It is unfortunate that debates encircling positivism have created a term that is infrequently used as a compliment and more often 'a term of epithet for someone else's work' (Johnson \& Duberley, 2003: 12). The positivist paradigm has greatly advanced our understanding of the physical world and has illuminated many interesting areas to be explored in-depth in the social sciences, including leadership.

However, a major problem in studying the phenomenon of leadership is associated with universality and generalizability, verifiability and the search for immutable truths. This problem includes the perceived need for replication of findings, regardless of contexts. Fleetwood and Hesketh (2006) have provided a persuasive critique of replication in social science research. This critique concludes that replication is not as powerful as is often suggested. If indeed leadership is a contextually based process of social influence, then arguably the only 'truth' that is universal is that all such universal leadership theories are fallible and could be disproved in the sense that all contexts are in some way unique. That is not to say that leadership is not real and does not have an affect. Rather, we emphasise the rather ubiquitous belief that the effect and manifestation of leadership varies by context and is perceived relatively. Such a suggestion raises the defiant proposition that it might not be possible to generalize about leadership research findings. The concomitant proposition would be that generalizability is not a valid criterion to test for the rigour of leadership research.

\subsection{Grounded theory and good science}

Grounded theory provides a methodological way forward to addressing our understanding of how to make sense of and explain the manifestation of contextualised leadership. Further, it may allow us to suggest causal explanations of the leadership manifestation in particular contexts and across contexts through levels of abstraction related to levels of analysis. We argue that the relative infancy of grounded theory as a methodology for leadership research does not have the seniority and legitimacy of more traditional quantitative approaches developed within the frame of positivism. Some principles of positivist science may clash with the purpose of grounded theory. For example, grounded theory seeks to understand people's words and actions in contexts and develop explanations through interpretation (Corbin \& Strauss, 2008). Issues of validity thus become difficult - someone else examining the data may generate an alternate explanation. A potential issue for the grounded theorist is how to represent their research to a scientific community when aspects of validity and generalization become problematic.

Scholars of grounded theory from outside of leadership studies have been able to obviate these criticisms by adopting a set of criteria of validity, reliability and rigour that were different from those adopted by the positivist scholars. For example, the need for generalizability of findings across a broader population was jettisoned in favour of the substantiveness of the findings to a particular population. Therefore, the plausibility of the findings to a lay reader is a component of the external validity of grounded theory findings. Representative sampling was jettisoned in favour of theoretical sampling. Fit and relevance were adopted as criteria for the validity of research findings. Maximum variety in data sources was seen as a ground for external validity. The evidence and credibility of the emergent phenomenon were preferred to traditional notions of validity and reliability.

In other fields, most notably sociology, grounded theory is more prominent and has become more established. In part this prominence relates to a greater acceptance of the contextualization of social processes. It also relates to epistemological 
eclecticism, perhaps in the form of a suspicion of positivism, and the greater prominence and influence of social constructionist perspectives. The work of Charmaz $(2000,2006)$ draws from a sociological perspective and argues the case for grounded theory to take a middle ground between postmodernism and positivism because the emergent theories are local, focus on generating meaning and 'we can adopt grounded theory strategies without embracing positivist leanings' (Charmaz, 2000: 510). The 'local' emphasis of constructivism is important for grounded theory because it anchors findings within a context. However, it also illustrates a point of departure between constructivists and critical realists. For constructivists there is an acceptance of multiple realities (Corbin, in Corbin \& Strauss, 2008, declares such a position). For the critical realist (in consort with the positivist) there is one reality that is usually interpreted differentially. But unlike positivists, (but in consort with constructivists) critical realists assume knowledge, as a social construct, to be transitive and temporary (Sayer, 1992). Emphasis is thus placed on ontology over epistemology. In essence this is the core concept shaping the arguments of this paper that grounded theory must place primacy on resonating with the reality of the substantive context.

A post-modern approach that denies reality cannot, by definition, generate theory that resonates with reality. Similarly there is a grave danger that positivist-orientated theory might not resonate with reality. This is because the positivist method dictates a sense of epistemological truth that must be adhered to. It is captured in Fleetwood's (2004: 2) phrase of 'scientism', which is similar to Charmaz's (2000) notion of 'scientistic'). Scientism reflects a belief that methods found successful in science are equally applicable to social science, including a belief that the epistemic criteria upon which the methods are based will lead to truths (Ackroyd, 2004: 141). If these criteria are met then the knowledge claim is objectively true, law-like and is universal (Dean, Joseph, Roberts, \& Wight, 2006: 53). Such a discourse leads to the notion of 'proven truth' that can be disconnected from the complex realities of particular contexts. Sayer (1992) advises that questioning foundationalist ideals of truth is unsettling. 'It is quite understandable that people should be wary of letting go of such a concept [truth], but some accommodation must be made between notions of fallibility and truth' (1992: 68). Rather than false or true, Dean et al. (2006: 53) argue that truth about the social world might be better understood through an epistemic semantic interpretation of knowledge. That interpretation would progress through a continuum of 'certain', 'obvious', 'evident', 'beyond reasonable doubt', 'probable' on the one hand; through 'probably false', 'clear to disbelieve', 'reasonable to disbelieve', 'evidently false', 'obviously false' and 'certainly false' on the other hand. Using the notion of scientism, a consequential research belief would suggest that Dean's thesis is inappropriate - claims are either proved or falsified. A corollary would be to suggest an assumption that there is only one approach to science and other philosophies of science, such as critical realism, are therefore doing something other than science - or at least not 'good science'.

\section{Critical realism: Also 'good science'}

It should be noted at this point that critical realism differs from many versions of critical studies. The latter has drawn from critical theory and post-structuralism notably through the edited writings of Willmott and Alvesson (1992). It examines underlying issues within organizational life often associated with power asymmetries and the privileging of particular discourses. Critical realists draw upon the notion of underlying power structures that might not be conscious to people yet have influence on the production of social reality. The thinking is similar to critical theory and the work of the Frankfurt School in some respects, but fundamentally different to the extent that critical realism does not share post-structural assumptions over the singular dominance of privileged discourse and its associated relative ontology.

For critical realists the social world is 'real', in the sense that it generates affect and exists independent of its identification (Ackroyd and Fleetwood, 2000: 11) and can be stratified into three levels of reality (Bhaskar, 1978):

- Empirical - observable by human beings

- Events - existing in time and space

- Real or 'Deep' - powers that are often unobserved yet causally efficacious

The term 'deep' is introduced by Fleetwood (2004) to limit confusion with the notion of real - as all three levels of reality can be seen as real. Additionally, the notion of deep captures a sense of difficulty in accessing and observing. The 'deep' reflects structures of the world that do not depend upon cognitive structures of humans (Margolis, 1986). Deep causal powers may not be capable of being observed through events, but rather are interpreted and explored though an understanding of the interplay between agency and structure (Archer, 1995, 2000; Reed, 1997). Archer's (1995: 294) notion of morphogenesis provides a useful frame to understand the operation of deep structures. She suggests that structures (for example embedded practices and meanings of leadership) pre-exist individuals and, as a consequence, individuals are influenced by such structures. Archer refers to individuals influenced by these structures as primary agents. They are unaware of the existence of structures and are unconsciously influenced by these structures and, through their ongoing action, sustain such structures. Individuals in positions of influence, described as corporate agents, may or may not be aware of the structures but through their actions are able to sustain (morphostasis) or elaborate (morphogenesis) such deep structures. In the examination of Case 2, later in this article, we explore the impact of deep structures on the development of practices and meanings of leadership using Archers work.

Most extant leadership research, including the methodology of grounded theory, has probed effectively into the first two levels of reality. We suggest that the 'deep' level of leadership reality has not been explored effectively thus far. This is understandable because such a level of reality is difficult to observe and measure. Strict adherents to the tenets of positivism might conceive of such exploration as fiction and not science. However for critical realists, explanation of the three levels of 
reality shaping the manifestation of leadership needs to be interpreted and explored through an understanding of this interplay between structures and agency (Archer, 1995; Bhaskar, 1978; Reed, 1997). The central feature of structure-agency interaction is encapsulated by Bhaskar (1989: 36) thus:

People do not create society. For it always pre-exists them and is a necessary condition for their activity. Rather, society must be regarded as an ensemble of structures, practices and conventions which individuals reproduce and transform, but which would not exist unless they did so.

A key critical realist principle is that no two organizational contexts are, under normal circumstances, the same - suggesting that replication is highly problematic. Rather, each context is configured into a complex nexus of influences (Fleetwood, 2004). We are not saying that contexts do not share similarities and common properties. For example, language is shared between contexts, and embedded in language are common assumptions, beliefs and practices. Within the field of leadership such common properties have been identified by House et al. (2004) to have global occurrence. However such properties occur transfactually - that is they might exist, but their ability to influence will vary according to other influences within a particular context. Thus, predictions and the creation of causal laws are similarly highly problematic (Ackroyd, 2000). Critical realists also seek to express the power of embedded meanings, practices and relationships as structures that affect people; yet such powers are themselves sustained by people (Porpora, 1989; Archer, 1995; Fleetwood, 2004). From this perspective context is constituted by:

- Structures - a nexus of embedded meanings, practices and relationships that pre-exist agents

- Agents - sustaining and elaborating meanings, practices and relationships

Therefore, structures causally affect agents' actions and, in turn, structures are causally affected by them.

The social context of leadership can be seen to be created through an interaction of structures and agency as a complex causal configuration (Fleetwood, 2004). This configuration is developed over many years and reflects the antecedents of structureagency interaction of groups, organizations, sectors and countries (Archer, 1995, 2000). There are examples of possible structures and conceptions that could be influencing the manifestation of leadership. These examples are drawn from extant leadership research and include leader behaviors, the structure-consideration dichotomy, or the transformation (as in transformational leadership). We are not attempting to pigeonhole a more encompassing approach into traditional notions of theory building. Rather, we are attempting to open avenues for those whose project is to seek to understand, even to generalize, leadership in all its complexity of processes and contexts.

These examples are universal conceptions at the highest level of abstraction. Critical realists would suggest that it is difficult to attribute local causation to these universal conceptions of leadership. Indeed, empirical research for many years has had great difficulty in attributing causal influence to the manifestation of leadership. Certainly in business research, for example, we are aware of no published research which 'proves' universally that leadership has a substantial causal impact upon organizational financial performance. This does not mean that it doesn't, but rather that contextualised causality might be more complex than is presupposed. Thus the causality of universal leadership theories might reflect Dean et al.'s epistemic criterion of being 'reasonable to disbelieve' (2006:53).

Additionally, individuals bring something of themselves to the enactment, causing relationships, practices and associated meanings of leadership to become modified over time. This process, akin to Archer's (1995) notion of 'morphogenesis' described earlier, is an argument for the temporal and processual manifestation of leadership. An important truism argued by Archer is that the social world exists only because of the actions of some persons, at some time, and is thus constructed from human agency and is subject to change from subsequent human action (similarly argued by Mingers, 2002 and Dobson, 2002). For leadership research, this argument is brought to life by the difficulty that researchers have in immediately transposing a leadership theory to a different cultural context, for example transposing transformational leadership to what might loosely be described as a 'Confucian' setting. The existing practices and meanings of leadership within the Confucian setting are internalised and enacted by agents. A transformational conception of leadership could thus be an alien concept. However, over time universal conceptions of leadership might begin to influence agents' actions leading to an elaboration of the 'Confucian' setting through time.

\subsection{Adjudicating on critical realist explanations}

An axiomatic but explicit assumption for critical realists is that any understanding and explanation of reality is fundamentally socially constructed. To wit, language is transient and a 'changeable artefact' (Rorty, 1982: 92). Reality is thus seen through the lens of language 'and although the truth may be out there we may never know it in an absolute sense' (Sayer, 1992: 162). If there are no epistemological truths how might we discriminate between explanations of a 'real' world? We suggest that an answer to this conundrum is through reliability, and validity oriented toward the primacy of ontology - that is resonating with reality.

An epistemological issue for critical realists is associated with the domain of the deep structures, reflected in causal powers that shape agency actions that may not be observable. Gordon (2002) has already identified the problematic influence of deep power structures upon leadership. By implication, he has also identified the difficulties encountered by extant methodologies in researching these constructs. Positivist criticisms of critical realism are levelled at both the issue of unobservable structures and non-empirical evidence, and the relativist epistemology that leads to knowledge justification becoming self-referential (Johnson \& Duberley, 2003). Put another way, if explanations are couched in terms of unobservable causal powers, how can we 
know anything about them? How can realists substantiate knowledge claims? As Halfpenny (1994: 65) astutely observes: 'What restrictions are there upon mechanisms which can be invoked as causal explanation ... why not demons and witches?'

For critical realists the answer, in part, appears to lie in a form of pragmatism (Johnson \& Duberley, 2003). Derived from the Greek word 'pragma', pragmatism was associated with knowledge that might guide human practice and purposes: a theory grasps enough of reality to allow us to do things with it. Sayer accepts that all social constructions of knowledge are fallible and as such knowledge of the social world is limited to providing epistemic gain. Such gain is toward 'practical adequacy' rather than truth. Practical adequacy of knowledge is defined by Sayer (1992: 69) as being able to:

'generate expectations about the world and about the results of our actions which are actually realised ... The reason that the convention 1, that we cannot walk on water, is preferred to convention 2 , that we can, is because the expectations arising from 1 but not 2 are realised ... It is not that our knowledge of water doesn't work, but rather that the nature of water make 1 more practically adequate than 2 '.

An associated validity criterion is that of plausibility. For the critical realist an internal validity question becomes whether or not the explanations thus provided give epistemic gain and are 'practically adequate' to the context from which they are drawn (Sayer, 1992). Such a view leads to the notion that validity is about developing a plausible explanation of reality (Dean et al., 2006: 53). Such a view also addresses generalization: underlying influences exist but whose effect in other contexts is contingent upon the interaction of certain other influences present in the specific context (Fleetwood, 2004).

For example, difficulties that might be experienced in applying transformational leadership theory to a different cultural context might not mean that transformational leadership theory is faulty or unreliable. It might merely mean that transformational leadership theory works differently in different contexts. Hence, when moving to a different context, items that were removed in an earlier factor analysis might have to be returned. The factor structure might be completely different. Indeed, a completely different set of factors might apply. In other words, transformational leadership is probably a plausible and reliable construct. It meets the criteria of pragmatism, practical adequacy and plausibility. However, it is highly likely that it will never have a consistently fixed and generalizable psychometric structure in all contexts. The present authors have found this situation to be the true on many occasions. Psychometric construct validity is often difficult to achieve, yet the manifestation of the factors is plausible to the research audience and entirely valid conceptually, theoretically and pedagogically. Parry and Sinha (2005) also make this argument persuasively.

This is a most significant point. Grounded theory seeks to develop an understanding or an explanation of a phenomenon within a particular context (Glaser \& Strauss, 1967). The technique constructs such an explanation by building up levels of abstraction (as per Kan \& Parry, 2004). This original conception of grounded theory, focused at 'grounding' theory development to help generate meaning (Charmaz, 2000) and explanation (Parry, 1998), embraces notions of pragmatism and necessity to correspond to local contexts.

Researchers who see leadership as a contextualised process might value the understanding of contextual variability and its influence on the manifestation of leadership. This desire might illuminate an approach to science that seeks to develop an explanation which resonates with the reality from whence it came. There is significant overlap in underlying assumptions between grounded theory as originally conceived and critical realist orientation of 'good' science, namely:

- Substantive theory building as a core goal, where a theory is a set of propositions designed to establish an explanation of a phenomenon in a particular context.

- A contextualised focus to understanding, explaining and theory development, related to levels of analysis, for example leadership within a team or a global manifestation of leadership.

- Hierarchy of theory abstraction.

- Use of metaphors and related (and unrelated) concepts and theories to aid substantive theory development.

The similarity enables us to suggest that a critical realist perspective of developing knowledge about the social world reflects the key tenets of grounded theory. Such coherence provides an enhanced perspective to be utilised by grounded theory researchers. This perspective would enable alternate epistemological criteria to be applied to internal validity, namely: practical adequacy and plausibility. In other words, and with particular reference to grounded theory, we generate theory that might guide human practice if the postulated theory makes sense to the context and to the individuals from which it is drawn. We will illustrate in Case 1 below an example of a published grounded theory where justification of the validity of the theory is judged against positivist epistemic claims. Rarely do researchers demonstrate that they have tested their theories for practical adequacy to see how useful the explanations are or that the explanation seems plausible to an audience that reflects the context of the research. A striking contrast is the declared position of Corbin (in Corbin \& Strauss, 2008: 273) where the necessity is emphasised of validating through reference back to interviewees. Generalization is sought through theoretical comparison. Suggested explanations of the social processes of leadership from one context are put forward for comparison to other explanations of alternative contexts. In this way the process of theoretical comparison echoes the principles of grounded theory - moving from a substantive theory toward connecting explanations that seek to establish a consolidated appreciation of the complex nature of leadership at higher levels of analysis. Explanation might be informative, helpful and illuminating, but very probably limited as an explanation of leadership within a local context.

To illustrate these arguments we have looked at two published accounts of grounded theory on leadership studies. One is an examination of leadership in a hospital setting and the second is an examination of the lived experience as leadership learning in a 
single organization. The first case was working within a positivist paradigm and stretching the boundaries of acceptance. The second was explicitly working within a critical realist epistemology. We contend that both cases could be taken further with greater use critical realist principles to realise an even greater contribution to theory and understanding.

\section{Case 1: Identifying paradox (Kan \& Parry, 2004)}

Case 1 researched the processes of nursing leadership in a major hospital. Data came mainly from interviews, observation, participant observation and survey questionnaire data using the psychometrically rigorous Multi-factor Leadership Questionnaire (MLQ; Bass \& Avolio, 1990). The implementation of data triangulation was a strength of this method. As Egri and Herman (2000) remind us, this data triangulation contributes to the internal validity of grounded theory research. Analysis was the full grounded theory method. Differences in findings between the questionnaire data and the interview/observation data were rectified to the satisfaction of the researchers through theoretical sampling and theoretical coding. The category at the highest level of abstraction was 'identifying paradox'. Within identifying paradox people who demonstrate leadership will reconcile the paradoxes that they and others were feeling, and thereby move the organization forward. Those who did not demonstrate leadership would legitimate or rationalize the paradoxes that were felt, and thereby retard the progress of the organization.

\subsection{Methodological tensions}

The main source of methodological tension was the discrepancy between the questionnaire results and the interview/ observation results. The questionnaire told us that leadership was present in approximately the same amount as the national norms. However, the interview and observational data identified that leadership was being compromised and repressed. Certainly, subsequent iterations of interviews and re-examination of the questionnaire data resolved the discrepancy with the emergence of mid-level categories. However, these differences were sorted out to the satisfaction of the researchers, and not necessarily to the satisfaction of the respondents. The plausibility and pragmatism of the explanation was established in the mind of the researcher. However, what would have been even more powerful was the active involvement of the participants in helping the researcher to understand the reality that was occurring. This is not to say that participant involvement is abdicating, or even diluting, the analytical expertise of the researcher. The researcher is still doing the analysis, but in such a scenario, the active involvement of the participants is in gathering data. Of course, any such involvement does not mean that we would necessarily have gained full access to underlying structures. Rather, we might have moved closer to reality by ensuring that the theory resonated with the experience of participants. The subjectivity associated with such involvement would strengthen the emerging theory, not weaken it.

One set of issues of validity and reliability revolved around the psychometric properties of the questionnaire. Another set of issues about validity and reliability revolved around the criteria for validity and reliability that relate to grounded theory and not to questionnaire research. These criteria are often mutually exclusive. However, this paradox was resolved by using psychometric criteria for validity and reliability to fine-tune the questionnaire data, and to apply grounded theory criteria for the analysis of the full set of data. Be that as it may, these issues were empirical, and not necessarily ontological.

The reviewers were after methodology, and not ontology. Therefore, the data were gathered and analysed correctly. At least, they were gathered and analysed to the satisfaction of reviewers who were trained to objectively assess research that utilised a subjectivist methodology. Therefore, the view of reality that emerged might still be inadequate. The reality that emerged was constrained by the cognition of the researchers and the reviewers.

\subsection{Developing theory}

The development of categories could not move beyond the data, as they were presented by the participants. The data were constrained by the observations and interpretations of the researchers. They were constrained also by the expressions and expressiveness of the participants. Certainly, it is axiomatic of grounded theory that the theory is grounded in the data. That is its strength. However, we are not advocating the reduction of the empirical support and validity of the emerging theory by ignoring the data and choosing to go beyond them. Instead, we are advocating that the emerging theory can be empirically stronger and more valid by utilising the data, as presented, and also going past the data the data to look for even deeper and more valid explanations.

Because the data participants were nurses and other health practitioners, the discourse was constrained to that used by the participants in their daily work lives. One researcher was trained as a musician and the other as an inventory manager. Both could use the discourse of their training to make greater sense of the data. Two possible problems emerged. First, both were limited to three discourses - health, music and inventory management. Second, both researchers experienced the paradox of three different and therefore potentially conflicting discourses across data and interpretation. Therefore, they experienced the twin drawback of discourse limitation and discourse conflict. These drawbacks are not weaknesses in the grounded theory method. They are merely constraints upon grounded theory maximising its efficacy. To move past these discourse constraints, via the philosophy of science of critical realism, would be to maximise the explanatory potential of the grounded theory method. 
The authors could have been more innovative than 'reconciling paradox'. After all, there is much existing leadership theory about the notion of the sense-making that involves the resolution of some form of paradox. Pye (2005) has articulated sensemaking as the essence of leadership, based around the sense-making thesis of Weick (1995). Smircich and Morgan (1982) have already put forward the proposition that leadership is essentially the management of meaning. Parry (1999) developed the theory of leadership as 'resolving uncertainty', utilising a grounded theory methodology. It could be concluded that there is little that is innovative or insightful about the leadership process of reconciling paradox. Of course, we cannot adequately reanalyse the data of Kan and Parry. If further iterations of interviews are necessary, the interviewees are now not available some years on.

We can only posit what might have happened had things been done differently. Be that as it may, had they conducted their grounded theory analysis through the frame of critical realism, they might well have developed an explanation that had a medical or nursing metaphor. Indeed, on one of the few occasions that the emerging theory was shared by Kan with a respondent, there was comment that the process model looked like a DNA helix. If Kan and Parry stayed with the idea of metaphor to explain their emerging process theory, they could just as easily have developed a more traditional leadership metaphor like a military or horticultural metaphor. But this was not to be. The explanation that emerged from this scientistic mode of grounded theory was the more mainstream notion of reconciling paradox. The researchers were almost constrained by the mindsets of the people who provided the data. They certainly seemed constrained within the parameters by their own pre-existing mindsets. They stayed within the scientistic, objective explanation of the leadership process, perhaps at the expense of sense-making in the mind of the reader. These comments are not a criticism of the grounded theory method. They are a reflection on the authors for not exploiting the full potential of this method.

A critical realist approach might have come up with something other than 'enhancing adaptability', or it might not have. In the spirit of grounded theory, the theoretical coding might have involved, for example, a work-in-progress hypothesis to explain the emerging phenomenon. This WIP hypothesis might have incorporated the critical realist approach by posing a non-traditional explanation, and then tested for its practical adequacy. The researchers might have arrived at the same explanation, or they might not. Either way, the analysis will have been enhanced and the resulting explanation of the phenomenon would have been more comprehensive. We are hoping that with the present article, we can provide a stimulus to others to help exploit that potential of grounded theory more fully.

\subsection{Methodological ambitions}

Kan and Parry's work suffered from an apparent refusal to break fully with the mindset of a positivistic philosophy of science. The objectivity of their analysis was rigorous and laudable. However, their work might be seen to be overly objective and insufficiently subjective. To get a richer explanation of the phenomenon and to get a more explanatory grasp of reality, their analysis needed to be more subjective. After all, it is agreed that their findings are substantive to a particular setting and not generalizable. Therefore, their analysis might have benefited from a more subjective approach which is likely to bring out more effectively the emotion of the lived experience of the participants.

Because of the substantiveness and non-generalizability of the research, Kan and Parry's analysis could have benefited from being more relative than absolute. Implicit within Kan and Parry's work was the notion that what is examined is what can be identified and what can be measured. The notion of identification and measurement is clearly represented by the use of the MLQ instrument. It is also represented by the use of the Six Cs of grounded theory analysis - cause, consequence, contingency, condition, covariance and context. This aspect of the method provides data and methodological triangulation. This also is laudable. However, it does so within pre-existing frames of reference. These frames of reference are about cause and effect and about an incremental addition to knowledge about pre-existing leadership constructs. This method was rigorous, but still smacked of scientific method. Clearly, an ambition of the researchers was to maintain rigour but also to break free further from the shackles of scientific method. To do so would enable them to uncover and even richer explanation of the reality of leadership in this substantive setting.

Hansen, Ropo, and Sauer (2007) remind us that leadership approaches rooted in scientific realism, like most of the social sciences, take a rational view that is often too narrow to describe the more complex human experiences of leadership. By contrast, the value of the subjectivism and relativism is demonstrated by the aesthetic perspective on leadership. As opposed to the objectivist and realist approaches to leadership phenomena, the aesthetic knowledge unleashes the tacit knowledge that is rooted in feeling and emotion. We recognize that the tacit knowledge of the participants in the Kan and Parry research remained hidden and needed to be freed so that the researchers could make use of it. In the case of this research, the reason and logic that the authors have given us with their empirical skill could well have been augmented by emotion and feeling, a strategy suggested by Hansen et al. (2007). This strategy would enhance the sensory knowledge and felt meaning that could be imparted to a readership. In turn, this knowledge would enhance the cognitive sense-making that, hopefully, has already occurred.

Perhaps the explanation that could have been forthcoming might have been explained in terms of a song or a film, maybe a screenplay - perhaps a black comedy or a farce - perhaps as a book or other narrative. Grint, 2000) uses historical stories as data, and as a form of data analysis. Perhaps in the case of identifying paradox, they could be used as findings or even as a component of the emergent theory. In addition to the excellent explanation of identifying paradox that Kan and Parry provided, they could have provided a richer, more aesthetic, valid and empirically persuasive theoretical explanation of this leadership phenomenon. The opportunities are many. 
The need to break further with this implicitly positivist mindset motivated Kempster's (2006) application of the grounded theory method in his work on leadership development. The question remains whether Kempster's application of the grounded theory method provided adequate insight to the reality that was in action.

\section{Case 2: Leadership learning as lived experience (Kempster, 2006)}

Case 2 examined how senior managers in a single organization believed they had learnt how to lead. Within Kempster's research he explores the problematic issue associated with tacit leadership learning and argues that it is important to make conscious the nuances associated with the learning of meanings and practices of leadership, and also the timing of that learning. His review of the extant research in this field identified a broad category of 'learning through doing' or experiential learning. Undoubtedly this captured the essence of the broad sweep of empirical data but did not address the recognised inherent 'tacit problem'. However using the work of Lave and Wenger (1991) and their arguments of situated learning and apprenticeship Kempster argued that leadership learning is more than experiential learning and that there is an important aspect of observation and participation drawn from a variety of contexts that is significant to the development of leadership practice.

The key methodological issue (as opposed to the research question) for the research project was described as 'how to move beyond the empirical level that has previously constrained explanations of leadership learning, while still maintaining epistemological rigour and validity?' In a sense traditional epistemological tenets would guide grounded theory to repeat the extant research and justifiably lead to a broad yet rather superficial category of experiential learning. But Kempster was cognisant of critical realist arguments of the 'deep' level of influences that may not be readily recognised by respondents as shaping their leadership learning and sought to interpret the data using a range of related learning theories.

\subsection{Methodological ambitions}

From the outset the research assumed a critical realist philosophy in that the explanation of leadership learning might be drawn from both surface experience and the deep embedded causal influences not necessarily recognised by respondents. The extant literature on naturalistic learning (Burgoyne \& Hodgson, 1983) provided clear guidance that learning might not be easily recalled but this does not mean it has not occurred. Kempster's goal for the research was to create an explanation of leadership learning.

The research followed Parry's (1998) technique of grounded theory. From the frame of critical realism this technique can be seen to move the data analysis from the empirical towards higher levels of abstraction. It allows the researcher to be informed by concepts or perhaps metaphors that help to develop an appreciation of possible underlying 'deep' influences on the manifestation of leadership learning. The internal validity of the explanation was tested with the respondents in order to explore the practical adequacy and plausibility of the explanation. In essence it was a substantive grounded theory of their experiences. Generalization was to be limited to a suggestion of possible underlying mechanisms shaping leadership learning capable of comparison to other contexts. Sayer (1992: 71) would remind us that 'our theories should be practically adequate, which work in other contexts, which are consistent to other knowledge and practices; our theories should explain the situation under study by giving an account of what produced it and not merely a way of deriving or calculating the results'.

\subsection{Developing a substantive theory through interpretation and abstraction}

A metaphor of 'apprenticeship' was used as the highest level of abstraction to explain leadership learning occurring in this particular substantive context. Associated with the metaphor was a set of associated themes that cohered together to form an explanation of leadership learning. None of the respondents mentioned this metaphor or the causal explanatory themes. Rather the extant literature, notably Lave and Wenger (1991), provided the insight to what may in part be occurring. Critical realism provided the substantiation to explore deeper, albeit not in an unscientific or speculative way. Rather it is the orientation of internal validity and the nature of external validity that differs from a positivist sense of 'good science'.

Following discussions with the respondents it helped them draw together their reflections as a set of enactments and relationships within particular contexts: the explanation seemed plausible. Additionally, the respondents were able to use the explanation to understand how they had learnt how to lead. In essence, they created an explanation that made sense to them - it was 'practically adequate'. The practical adequacy of the metaphor and related concepts of situated learning provided justification for going deeper into data interpretation and abstraction. Kempster felt he was doing the right things. This is not to say that a metaphor is always going to be the end result of critical realist grounded theory analysis. However, it was a pragmatic explanation of reality in this case, and there is a broad literature that supports and validates the sense-making effect of metaphors (Oswick, Keenoy, \& Grant, 2002; Oswick, Putnam, \& Keenoy, 2004; Palmer \& Dunford, 1996; Putnam \& Boys, 2006). The challenge became how to justify what had been discovered. The question was whether this would be considered 'good science'. Fig. 1 represents the emergence of apprenticeship from 'beyond the data'.

\subsection{Methodological tensions}

One positivist criterion for 'good science' is the external validity for populations beyond the present sample. This criterion is much less relevant to this research. If the explanation is applied in other contexts and is seen as useful (practically adequate), 


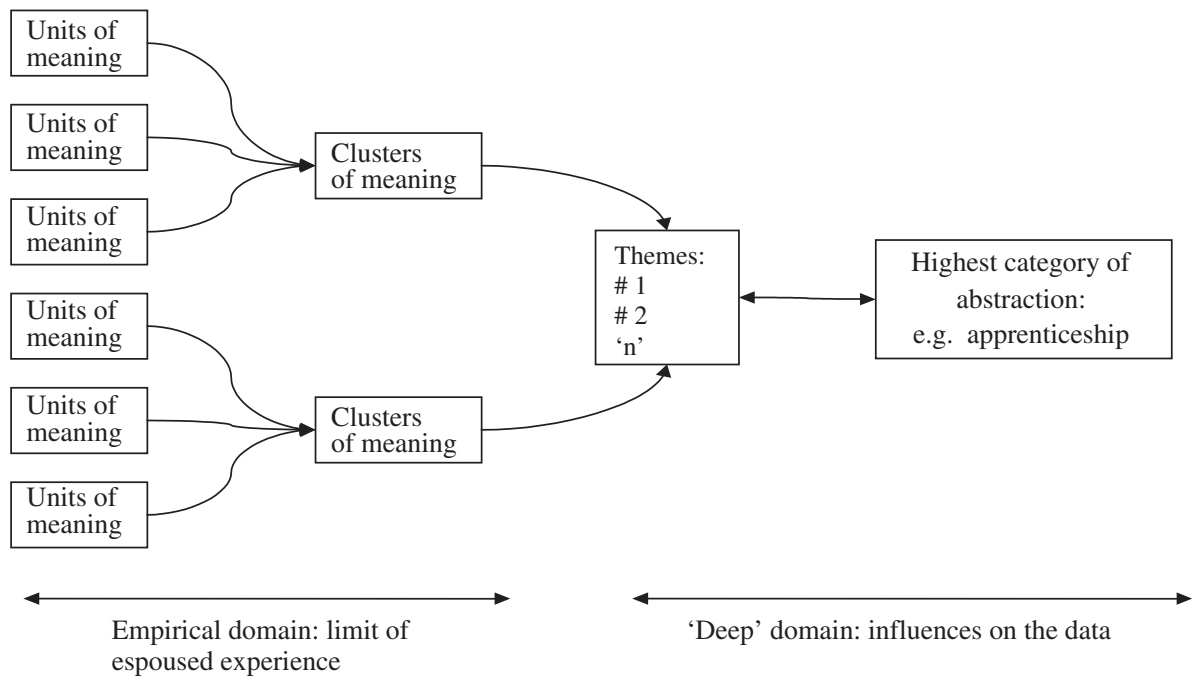

Fig. 1. Grounded theory of leadership development as apprenticeship: a retroductive argument (Kempster, 2006).

then the 'deep' causal influences might be generalizable to other contexts. This research sought to triangulate the emerging theory across the range of respondents. But, despite this emphasis on corresponding with reality, Kempster was uncomfortable and unconfident with his approach in terms of publication because the received wisdom still lay in positivist criteria. His strategy was to minimize discussion on critical realism and maximise grounded theory as a robust process for illustrating qualitative analysis. He deliberately used the language of theoretical sampling and celebrated the in-depth visibility of data collection and data analysis techniques.

Had he not looked at this research through the lens of critical realism at all, different results might have emerged. For instance, had he conducted conventional grounded theory, what might have emerged was something like 'experiential learning' as the core category at the highest level of abstraction. Something like that, anyway. Such a core category would have been plausible, to be sure, but perhaps only modest in its claims for practical adequacy of developing the respondents understanding of the development of their leadership learning. Such a core category sounds bland, unemotive and faddish, predictable even; just as Kan and Parry's 'reconciling paradox' now sounds in retrospect. The abstraction and objectivism of such a core category might have made it a less efficacious reality in the minds of participants than the core category of 'apprenticeship' that did evolve.

The reviewers, as with the Kan and Parry research, were after conventional grounded theory methodological rigour. In other words, they were after findings that were closely grounded in the data that presented themselves. Inter alia, they were concerned with sample size and how this issue could warrant a contribution. Additional concerns evolved around the arguments being drawn from too many sources of literature and that there needed to be greater focus and specificity. Further, the reviewers were anxious over the claims that were not substantiated in the data-more anecdotal than factual. These concerns illustrated the understandable epistemological assumptions of one or more of the reviewers. The paper was presented and re-written with a sense of epistemological dissonance. The researcher was not celebrating the resonance of the arguments of the paper, or internal validity with the lived experience of the respondents. Rather the paper's focus was reoriented towards justification of the arguments from within the confines of empirical data. It is possible that a reader of the paper may think 'the argument makes some sense but I cannot see how this is drawn from the presented empirical research'. The issue of confidence described in this paper was echoed in this case. A significant issue for leadership research is whether this epistemological argument matters.

\subsection{How is the tension resolved?}

If the leadership phenomenon is mainly about complex social relationships within discrete contexts, then as researchers we need to be liberated to make the best sense of this in order to explain what is happening. We seek the best way to explain the contextualised phenomenon in question. For sure we need techniques that are reliable and valid as well as rigorous, for exploring and explaining phenomena. On the other hand, perhaps we should place emphasis on ontology and on the pursuit of a phenomenon that resonates with and reflects reality, rather than a strict view that defines an epistemological truth. Invariably truth is a far more complicated phenomenon than simply rendered 'not falsified'. Perhaps we might allow Dean et al.'s (2006: 53) epistemological hierarchy to shape our interpretation where truth might be certain, beyond doubt or perhaps simply probable. Corbin and Strauss (2008: 298) called this 'truth in a more pluralistic than traditional sense'. In this way we contend that within the field of leadership studies there will be numerous ontological cul-de-sacs generated through the measurement of constructs in search of immutable generalised truths for a highly contextualised phenomenon such as leadership. 
In Case 2 the philosophic assumption of the researcher was sympathetic to the notion of a stratified reality. In other words there may be deep influences on the manifestation of reality and as a consequence these might be unobservable. In Case 2 the author suggests an explanation that sought to embrace such a stratified perspective. Undoubtedly this claim cannot be justified epistemologically as 'proven'. In the context of qualitative grounded theory research this would not be the epistemological target. However, if justification is toward being 'probable' through demonstrating correspondence with and application to a respondent's contextualised reality, then in terms of grounded theory research there is the potential for significant contributions that could otherwise have been dismissed as being scientifically weak.

The two cases provide a contrast. In Case 1 epistemologically rigorous grounded theory was undertaken. Yet, the findings were not anchored as firmly as they could have been in the reality of the respondent. Case 2 was exorcised by epistemological tensions whilst seeking to pursue a grounded theory approach which was still anchored in the reality of the respondent.

\section{Conclusion-doing grounded theory even better}

We have identified calls for greater use of qualitative methods for leadership research in organizational settings. These calls have been answered, with increasing enthusiasm since about the time of Conger's (1998) argument that qualitative approaches are perhaps the methodology of choice for contextually rich topics, such as leadership. Moreover, we have argued that leadership is a social process of influence. Also, grounded theory is a very suitable methodology for exploring and seeking to explain processual and social relationships such as leadership. In particular, grounded theory is relevant for the exploration of leadership processes within particular distinct or unique contexts. However, the comparative recency of the use in organizational settings of these methods for leadership research, has led researchers to justify their research with positivist criteria.

Therefore, the main proposition we are positing is to argue that this epistemology has distracted the focus of researchers. Certainly, we believe this to be so within a 'business' or 'management' paradigm, at least. The positivist paradigm understandably leads the researcher to question validity if the theory does not measure up to statistical tests, despite the theory having resonance with reality. In essence such a paradigm is giving prominence to epistemology over ontology. This focus is at risk of being distracted from grounding theoretical arguments within the worlds of the respondents. Therefore, we suggest that applying a critical realist frame of reference to grounded theory research can augment the strengths of the grounded theory method.

\subsection{Critical realism and grounded theory: Internal validity and generalization}

By clarifying the epistemological foundation of grounded theory, researchers can become much more confident and assured that they are 'doing the right things' (ontologically) and 'doing things right' (epistemologically). Critical realism places prominence on ontology over epistemology. In this sense internal validity of a substantive grounded theory is oriented toward resonating with reality. If the grounded theory connects to peoples lived experience and also provides explanation and sensemaking, then we have epistemic gain through practical adequacy. That is, we have a better yet still fallible glimpse of reality. It is fallible in the sense that all knowledge is socially constructed through discourse (Sayer, 1992). Therefore, critiques should examine correspondence and tolerance with reality (ontology) rather than degree of fit to what Charmaz (2000) and Fleetwood and Hesketh (2006) might call fallible 'scientistic' procedures and epistemological 'truths'. Having said that, we need to reinforce the importance of empirically sound research. We certainly are not suggesting that 'doing the right things' will compensate for doing poor research. We are not suggesting that critical realism replaces grounded theory; or that in some way there is a critical realist grounded theory technique. Critical realism provides an alternative philosophy of science; an alternative to the positivism that has dominated leadership research. This alternative is very suited to grounded theory and specifically to leadership studies.

Critical realism allows researchers flexibility in the interpretation of the data and comfort in validity terms from not being constrained within the data. Researchers can accept that respondents might not consciously be aware of or be able to describe or appreciate social processes shaping leadership manifestation. For example, respondents may learn from experiences but not be aware consciously that they are learning. Therefore, we might not be able to immediately access such learning explicitly through empirical data. This is arguably a situation that is uncomfortably, albeit indirectly recognised by some grounded theorists, for example Locke (2001). It is a situation alluded to beautifully by Stablein (2006) in a summary of literature about data in organizational studies. Indeed, there is a considerable literature on interviewing technique that illuminates the necessity to go 'further' than the data and interpretively deeper into the data. Examples of this literature come from Ellis and Berger (2003) and Denzin and Lincoln (2005).

\subsection{Limitations}

There is an explicit limitation on critical realism that explanations do not seek to infer generalization beyond the substantive study because no two contexts are the same. Different contexts might share similar properties but each configuration of such properties, over-laden by unique histories and evolved practices, is a unique mix. Thus universality is highly problematic. If anything, this approach to grounded theory might suffer the limitation of over-interpretation of site-specific effects. Indeed, the site-specific substantiveness of this approach to grounded theory might mean that certain critical information is not accessed. At best, critical realists suggest tendencies toward applicability in other contexts, as suggested by Fleetwood (2004). Grounded theorists should have no problems with such a position, with the notion of substantiveness, and not generalizability, being 
axiomatic of the method. In addition Charmaz (2000), from a constructivist perspective, suggests that other researchers can explore and make their judgments as to how the substantive theory might fit other contexts and extrapolate whether a theory from one context is generalizable to another.

\subsection{The benefits of a critical realist orientation for grounded theory}

This article has argued that the principal tenets of grounded theory correspond closely with the philosophical position of critical realism. The possibilities of explaining social processes of leadership and leadership development in much greater detail through a critical-realist-informed grounded theory approach provide considerable additional opportunity for leadership researchers. This outcome might be achieved by:

- Placing emphasis on the contextual understanding and explanation of the social processes of leadership and leadership development, rather than on seeking 'universal truths' about leadership per se through measurement.

- Assuming contextual variation in leadership processes, and seeking to look across varying research outcomes for similarities and differences to build up a body of knowledge on social processes of leadership. Admittedly, this process might come after each distinct research project is completed.

The above two elements are not a surprise to grounded theorists. The significant added value of an underpinning critical realist philosophy of science to these points would provide confidence for qualitative researchers to remove the shackles of 'doing things right'. They might gain the freedom to experiment, be creative 'and be unafraid to draw on their own experiences having rejected more traditional ideas of objectivity and the dangers of using personal experience' (Corbin \& Strauss, 2008: 13). The re-orientation of internal validity towards resonating with reality might encourage a deepening of the contextualised appreciation of leadership processes. It would provide sufficient epistemological balance for researchers to be confident that they are 'doing the right things' and 'doing things right'. They will be conducting rigorous and methodologically robust research, and adding to the body of knowledge about the reality of the human condition more effectively.

What would such research look like? We are not attempting to be prescriptive or to reinvent the grounded theory wheel. However, we posit that grounded theory organizational research, if guided by the frame of critical realism would have the following characteristics:

1. Place an emphasis on context-rich qualitative data collection. This direction is in contrast to the context-free objectivity that presently drives much grounded theory research.

2. Awareness of a stratified reality and that the empirical data may be influenced by underlying mechanisms.

3. Draw on the ideas and theories of extant knowledge (whether related or unrelated) in order to analyze the data, rather than necessarily leaving extant knowledge in abeyance until analysis is complete. This might actually be a relief to many grounded theory researchers who anguish over when to integrate extant theory and how to keep it in abeyance.

4. Generate explanations that are either drawn explicitly from the empirical data or are postulated to be occurring. The use of metaphor as explanation, as per the Kempster research, is but one way that this might occur.

5. A grounded theory is suggested that seeks to understand and explain social processes of leadership within a particular context. It would test the usefulness of the emerging explanation with respondents from the context. The objective of this test is to determine whether the theory and explanation of the leadership process 'makes sense' from the experience of those respondents. It provides a better glimpse of the reality and the causes shaping that reality; and the proposed theory grasps enough of reality to allow the respondents to make use of it. This involves a test for the practical adequacy of the emerging theory from the perspective of the people closely involved with the context from which it was derived. However, the responsibility for theory development still rests with the researcher, and not with the respondents.

6. Be 'offered up' for other researchers to critique for its usefulness in other contexts. The aim is not to prove or disprove but rather compare explanations for similarities and differences. At high levels of abstraction there may be some convergence of explanation related to intransitive underlying influences affecting leadership manifestation. The importance of this tactic would include an ability to explain this convergence as related to a specific context or level of analysis, as suggested by Fleetwood (2004).

When reflecting upon Bryman's (2004) call for the qualitative research of leadership studies to be both contextualised and generative, we assert that a critical realist-informed grounded theory approach is a useful underpinning framework to move us toward both these goals.

\section{Acknowledgements}

We thank Steve Fleetwood for his help in brining this article to fruition.

\section{References}

Ackroyd, S. (2000). Methodology for management and organisation studies: Some implications of critical realism`. In S. Fleetwood \& S. Ackroyd (Eds.), Realism in action in management and organisation studies (pp. 3-25). London: Routledge. 
Ackroyd, S. (2004). Methodology for management and organisation studies: Some implications of critical realism. In S. Fleetwood \& S. Ackroyd (Eds.), Realism in action in management and organisation studies. London: Routledge.

Ackroyd, S., \& Fleetwood, S. (2000). Realist perspectives on organization and management. London: Routledge.

Archer, M. (1995). Realist social theory: The morphogenetic approach. Cambridge: Cambridge University Press.

Archer, M. (2000). Being human: The problem of agency. Cambridge: Cambridge University Press.

Barker, R. A. (2001). The nature of leadership. Human Relations, 54(4), 469-494.

Bass, B. M., \& Avolio, B. J. (1990). Manual for the multifactor leadership questionnaire. Palo Alto: Consulting Psychologist Press.

Bess, J. L., \& Goldman, P. (2001). Leadership ambiguity and K-12 schools and the limits of contemporary leadership theory. The Leadership Quarterly, 12(4), 419-450.

Bhaskar, R. (1978). A realist theory of science. New York: Harvester Press.

Bhaskar, R. (1989). Reclaiming reality: A critical introduction to contemporary philosophy. London: Verso.

Bryman, A. S. (1996). The importance of context: Qualitative research and the study of leadership. The Leadership Quarterly, 7(3), 353-370.

Bryman, A. S. (2004). Qualitative research on leadership: A critical but appreciative review. The Leadership Quarterly, 15(6), 729-769.

Bryman, A., Bresnen, M., Beardworth, A., \& Keil, T. (1988). Qualitative research and the study of leadership. Human Relations, $39,65-79$.

Bryman, A. S., Stephens, M., \& Campo, C. (1996). The importance of context: Qualitative research and the study of leadership. The Leadership Quarterly, 7(3), 353-370.

Burgoyne, J. G., \& Hodgson, V. E. (1983). Natural learning and managerial action: A phenomenological study in the field setting. Journal of Management Studies, 20(3), $387-399$.

Charmaz, K. (2000). Grounded theory and methodology: Objectivist and constructivist methods. In N. K. Denzin, \& Y. S. Lincoln (Eds.), Handbook of Qualitative Research (2nd ed.). London: Sage.

Charmaz, K. (2006). Measuring pursuits, marking self: Meaning construction in chronic illness. International Journal of Qualitative Health and Well-Being, 1(1), 27-37.

Conger, J. A. (1998). Qualitative research as the cornerstone methodology for understanding leadership. The Leadership Quarterly, 9, $107-121$.

Conger, J. A., \& Toegel, G. (2002). A story of missed opportunities. In K. W. Parry \& J.R. Meindl (Eds.), Grounding leadership theory and research: Issues and perspectives and methods (pp. 175-197). Greenwich, CT: Information Age Publishing.

Corbin, J., \& Strauss, A. L. (2008). Basics of Qualitative Research (3rd ed.). Thousand Oaks, CA: Sage.

Dachler, H. P., \& Hosking, D. -M. (1995). The primacy of relations in socially constructing organizational realities. In D. -M. Hosking, H. P. Dachler, \& K. J. Gergen (Eds.), Management and organization: Relational alternatives to individualism. Aldershot: Avebury.

Day, D. (2000). Leadership development in the context of on-going work. Leadership Quarterly, 11(4), $581-613$.

Dean, K., Joseph, J., Roberts, J. M., \& Wight, C. (2006). Realism, philosophy and social science. London: Palgrave Macmillan.

Denzin, N. K., \& Lincoln, Y. S. (Eds.). (2005). The Sage Handbook of Qualitative Research (3rd ed.). London: Sage.

Dobson, P. J. (2002). Critical realism and information systems research: Why bother with philosophy? Information Research, 7(2) [Available at. http://InformationR. net/ir/7-2/paper124.htm

Easterby Smith, M., Thorpe, R., \& Lowe, A. (2002). Management research: An introduction (2nd ed.). London: Sage.

Egri, C. P., \& Herman, S. (2000). Leadership in the North American environmental sector: Values, leadership styles and contexts of environmental leaders and their organizations. Academy of Management Journal, 43(4), 571-604.

Ellis, C., \& Berger, L. (2003). Their story/my story/our story: Including the researcher's experience in interview research. In J. F. Gubrium \& J.A. Holstein (Eds.), Postmodern interviewing (pp. 157-183). London: Sage Publications.

Fassinger, R. E. (2005). Paradigms, praxis problems and promise: Grounded theory in counseling psychology research. Journal of Counseling Psychology, 52(2), $156-166$.

Fleetwood, S. (2004). The ontology of organisation and management studies. In S. Fleetwood \& S. Ackroyd (Eds.), Realism in action in management and organisation studies. London: Routledge.

Fleetwood, S., \& Hesketh, A. (2006). Prediction in social science: The case of research on the human resource management-organisational performance link. Journal of Critical Realism, 5(2), 228-250.

Glaser, B. G. (1978). Theoretical sensitivity: Advances in the methodology of grounded theory. Mill Valley, CA: Sociology Press.

Glaser, B. G. (1992). Basics of Grounded Theory Analysis. Mill Valley, CA: Sage.

Glaser, B. G., \& Strauss, A. L. (1967). The discovery of grounded theory: Strategies for qualitative research. Chicago: Adeline Press.

Gordon, R. D. (2002). Conceptualizing leadership with respect to its historical-contextual antecedents to power. The Leadership Quarterly, 13 (2), $151-167$.

Grint, K. (2000). The arts of leadership. New York: Oxford University Press.

Groff, R. (2004). Critical realism, post-positivism and the possibility of knowledge. London: Routledge0-415-33473-X.

Halfpenny, P. (1994). Causality. In W. Outhwaite \& T. Bottomore (Eds.), The Blackwell Dictionary of Twentieth Century Thought (pp. 65). Oxford: Blackwell.

Hansen, H., Ropo, A., \& Sauer, E. (2007). Aesthetic leadership. The Leadership Quarterly, 18(6), 544-560.

House, R. J., Hanges, P. J., Javidan, M., Dorfam, P. W., Gupta, V., \& Associates (2004). Leadership, culture, and organizations: The GLOBE study of 62 societies. Thousand Oaks, CA: Sage.

Hunt, J. G. (1991). Leadership: A new synthesis. Newbury Park, CA: Sage.

Johnson, P., \& Duberley, J. (2003). Understanding management research. London: Sage.

Jones, R., \& Kriflik, G. (2006). Subordinate expectations of leadership within a cleaned-up bureaucracy: A grounded theory study. Journal of Organizational Change Management, 19(2), 154-172.

Kan, M. M., \& Parry, K. W. (2004). Identifying paradox: A grounded theory of leadership in overcoming resistance to change. The Leadership Quarterly, 15(4), 467-491.

Kempster, S. (2006). Leadership learning through lived experience. Journal of Management E Organization, 12(1), 4-22.

Lave, J., \& Wenger, E. (1991). Situated learning: Legitimate peripheral participation. Cambridge: Cambridge University Press.

Lewis, P. (1999). Metaphor and critical realism. In S. Fleetwood (Ed.), Critical realism in economics: Development and debate (pp. 83-101). London: Routledge.

Locke, K. (2001). Grounded theory in management research. London: Sage.

Locke, E. A., Kirkpatrick, S., Wheeler, J. K., Schneider, J., Niles, K., Goldstein, H., Welsh, K., \& Chah, D. O. (1991). The essence of leadership: The four keys to leading successfully. New York: Lexington Books.

Lowe, K. B., \& Gardner, W. (2000). Ten years of the leadership quarterly: Contributions and challenges for the future. The Leadership Quarterly, 11(4), 459-514.

Margolis, J. (1986). Pragmatism without foundations: Reconciling realism and relativism. Oxford: Blackwell.

Meindl, J. R. (1995). The romance of leadership as a follower-centric theory: A social constructionist approach. The leadership quarterly, 6(3), 329-341.

Mingers (2002). Future directions in management science modeling. In S. Fleetwood \& S. Ackroyd (Eds.), Realism in action in management and organisation studies (pp. 164-193). London: Routledge.

Nadler, D. A., \& Tushman, M. L. (1990, Winterr). Beyond the charismatic leader: Leadership and organizational change. California Management Review, 32 (2), $77-97$.

Osborne, R. H., Hunt, J. G., \& Jauch, L. R. (2002). Toward a contextual theory of leadership. The Leadership Quarterly, 13(6), 797-837.

Oswick, C., Keenoy, T., \& Grant, D. (2002). Metaphors and analogical reasoning in organization theory: Beyond orthodoxy. Academy of Management Review, 27 (2), $294-303$.

Oswick, C., Putnam, L. L., \& Keenoy, T. (2004). Tropes, discourse and organizing. In D. Grant, C. Hardy, C. Oswick, \& L. Putnam (Eds.), The Sage handbook of organizational discourse (pp. 105-127). London: Sage.

Palmer, I., \& Dunford, R. (1996). Understanding organizations through metaphor. In C. Oswick \& D. Grant (Eds.), Organization development: Metaphorical explorations (pp. 7-20). London: Pitman.

Parry, K. W. (1998). Grounded theory and social process: A new direction for leadership research. The Leadership Quarterly, 9(1), 85-105.

Parry, K. W. (1999). Enhancing adaptability: Leadership strategies to accommodate change in local government settings. Journal of Organizational Change Management, 12(2), 134-156

Parry, K. W., \& Sinha, P. (2005). Researching the trainability of transformational organizational leadership. Human resource development international, 8(2), $165-183$.

Pawson, R., \& Tilley, N. (1997). Realistic evaluation. London: Sage.

Porpora, D. V. (1989). Practice: Exploring links between experience and reflective practice. Adult Education Quarterly, 48(2), 98 -112.

Putnam, L. L., \& Boys, S. (2006). Revisiting metaphors and organizational communication. In S. R. Clegg, C. Hardy, T. B. Lawrence, \& W. Nord (Eds.), The Sage handbook of organization studies (pp. 540-576). London: Sage. 
Pye, A. (2005). Leadership and organizing: Sense-making in action. Leadership, 1(1), 31-50.

Reed, M. (1997). In praise of duality and dualism: Rethinking agency and structure in organisational analysis. Organization Studies, $18(1), 21-42$.

Roberts, C. A. (2002). Grounded theory: Creating valued leadership research through partnering. In K. W. Parry \& J.R. Meindl (Eds.), Grounding leadership theory and research: Issues, perspectives and methods (pp. 149-158). Greenwich, CT: Information Age Publishing.

Rorty, R. (1982). Consequences of pragmatism (Essays: 1972-80). Minneapolis: University of Minnesota Press.

Rowland, P., \& Parry, K. W. (2009). Consensual commitment: A grounded theory of the meso-level influence of organizational design on leadership and decisionmaking. The Leadership Quarterly, 20(4), 535-553.

Sandberg, J. (2001). The constructions of social constructionism. In S. Sjostrand, J. Sandberg, \& M. Tyrstrup (Eds.), Invisible management: The social construction of leadership (pp. 28-48). London: Thompson Learning.

Sayer, A. (1992). Method in social science; a realist approach. London: Routledge.

Silverman, D. (2001). Interpreting qualitative data: Methods for analysing talk, text and interaction (2nd ed.). London: Sage.

Sookal, L., \& Hanlon, D. (2002). A grounded leadership theory with insights into entrepreneurship. In K. W. Parry \& J.R. Meindl (Eds.), Grounding leadership theory and research (pp. 79-108). Greenwich: Information Age Publishing.

Smircich, L., \& Morgan, G. (1982). Leadership as the management of meaning. Journal of Applied Behavioural Science, 18, 257-273.

Stablein, R. (2006). Data in organization studies. In S. R. Clegg, C. Hardy, T. B. Lawrence, \& W. R. Nord (Eds.), Handbook of organization studies (pp. 347-369). (2nd ed.). London: Sage.

Strauss, A., \& Corbin, J. (1998). Basics of qualitative research: Grounded theory procedures and techniques (2nd ed.). Newbury Park: Sage Publications, Inc.

Weick, K. E. (1995). Sensemaking in organizations. Thousand Oaks, CA: Sage.

Willmott, H., \& Alvesson, M. (1992). Critical theory and management studies: An introduction. In M. Alvesson \& H. Willmott (Eds.), Critical Management Studies. London: Sage.

Xiao, Y., Seagull, F. J., Mackenzie, C. F., \& Klein, K. (2004). Adaptive leadership in trauma resuscitation teams: A grounded theory approach to video analysis. Cognition, Technology \& Work, 6(3), 158-164.

Yukl, G. (1998). Leadership in organizations (4th ed.). Upper Saddle River, NJ: Prentice Hall.

Zaccaro, S. J., Rittman, A. L., \& Marks, M. A. (2001). Team leadership. The Leadership Quarterly, 12(4), $451-483$. 